Arena 



\title{
A soberania do mal: Georges Bataille e a inocência culpada da literatura*
}

\author{
Philippe Joron**
}

\section{Resumo}

Em seu ensaio crítico sobre La littérature et le mal (1957), Georges Bataille usa todo um arsenal de conceitos e ideias interligadas para dar conta da Soberania do mal em Literatura e, ao mesmo tempo, da soberania da Literatura pelo mal. Com base em pesquisa bibliográfica, o objetivo do estudo aqui proposto será mostrar que esses mesmos conceitos e opções de pensamento já vinham sendo trabalhados em muitos escritos anteriores filosóficos, econômicos e políticos, ou mesmo místicos, que podem formar a base da sociologia heurística do autor. Para Bataille, a Literatura é comunicação. Ela parte de um autor soberano, passa pela servidão de um leitor isolado, e se destina a uma humanidade soberana.

Palavras chave: Literatura. Mal. Comunicação. Heterogeneidade. Núcleo sagrado.

\section{La Souveraineté du mal. Georges Bataille et l'innocence coupable de la littérature}

\section{Résumé}

Dans son essai de critique littéraire La littérature et le mal (1957), Georges Bataille utilise tout un arsenal de notions et d'idées-forces se répondant les unes aux autres pour rendre compte de la Souveraineté du Mal en Littérature et ce qui revient presque au même, de la Souveraineté de la Littérature par le Mal. Basé sur la recherche bibliographic, l'étude proposée ici s'appliquera à montrer que ces mêmes notions et options de pensée étaient déjà à l'œuvre dans nombre

\footnotetext{
* Tradução: Camila Escudero

** Professor do Departamento de Sociologia e Demografia, Centro de Ciências Humanas e Sociais, Universidade Paul-Valéry III, de Montpellier. Membro do Conselho Nacional das Universidades, Seção n. 19. Membro do Conselho Laboritorial LERSEM-IRSA/CRI E.A. 4584, Laboratório de Estudos e Pesquisas em Sociologia e Etnografia de Montpellier. Montpellier, França. E-mail: philippe. joron@univ-montp3.fr
} 
d'écrits antérieurs de nature philosophique, économique et politique, voire mystique, pouvant constituer le socle heuristique de sa sociologie. Pour Bataille, la Littérature est la Communication. Elle fait partie d'un auteur souverain, passe par une servitude de un lecteur isolé, et est destiné à une humanité souveraine. Mots-clés: Littérature. Mal. Communication. Hétérogénéité. Noyau sacré.

\section{The sovereignty of evil: Georges Bataille and the culpable innocence o literature \\ Abstract}

In his critical literature essay The literature and Evil (1957), Georges Bataille use a panoplies of key ideas intertwined to justify the Sovereignty of Evil in Literature and, at the same time, the Sovereignty of Literature by Evil. Using a research bibliographic, the aim of this paper is to show that this notions and options of thought have been already present in various anterior philosophical, economical and political works, even mystical, and its may constitute the heuristic base of his sociology. To Bataille, the Literature is Communication. It begins in a sovereign author, it passes by the serfdom of an isolated reader, and it arrives in a sovereign humanity.

Keywords: Literature. Evil. Communication. Heterogeneity. Sacred Nucleus.

$\mathrm{N}$

o ensaio crítico La littérature et le mal, de 1957 e que incorpora uma série de artigos publicados originalmente no jornal Crítica, Georges Bataille (1897-1962) tece uma ideia assustadora e atormentada sobre a liberdade de ser de cada face frente a imperativos que impõem outros autores. Amplamente explorado pela filosofia, nunca esta linha de pensamento, carnal, em muitos aspectos, deixou de guiar a vida e obra do autor. Esta liberdade, em estado desejado de explosão, e entendida como soberania, é o centro de suas diferenças filosóficas, seus desdobramentos sociológicos, arranjos antropológicos e, para bem dizer, de suas efusões literárias nas quais o autor não hesitou em praticar a pornografia, a escatologia e a depravação para dar significado à essência do laço social que esgota os seus atos em todos os tipos de imaginário, por mais escandalosos que eles sejam.

Três perspectivas emergem da leitura deste estudo, que pode permear tantos níveis de análise. À primeira vista, é mais ou menos um teste da crítica literária aplicado a algumas obras e vidas de autores que traduziram a problemática da liberdade em um confronto 
contínuo com o mal, com sua externalização inventada a partir de várias peças colocadas numa espécie de monte, com preceitos morais imbutidos que o seguram, fornecendo algum apoio. $\bigcirc$ foco é, portanto, em oito escritores que deram corpo, segundo Bataille, a esta liberdade culpada. São eles: Emily Bronte, Charles Baudelaire, Jules Michelet, William Blake, Donatien de Sade, Marcel Proust, Franz Kafka, Jean Genet. Trata-se então, num segundo momento, de um teste espelhado em sua própria produção literária - parte publicada clandestinamente e sob vários pseudônimos ${ }^{1}$. Finalmente, numa terceira perspectiva, é ainda uma oportunidade para o autor explorar a explosão de realidade na ficção, para analisar a ligação entre os nós da ideia de um mal genérico e o de uma literatura soberana, mostrando as consequências da obra literária sociológica sob este tipo de registro, além de permear aspectos psicológicos subjacentes a uma possível comunicação entre produtor e receptor.

Vamos nos abster de tratar aqui das duas primeiras dimensões do teste em questão: a análise, crítica visível aplicada às obras envolvidas ou os comentários que foram propostos, além do culto à introspecção literária e pessoal. Vamos nos ater apenas na terceira perspectiva, que não é a mais ampla: é a que, de algum modo, condensa toda sociologia de Bataille em um apanhado de noções chaves, ou conceitos fundamentais, que renovam uns aos outros. Na verdade, bem como seu estudo de erotismo publicado no mesmo $\mathrm{ano}^{2}$, La littérature et le mal também deve ser entendida não só à luz das linhas de força, mas também sob rachaduras e fraturas (epistemológicas ou temáticas), que constituem o aparato crítico da sociologia do autor na segunda metade de sua vida.

Bataille introduz suas propostas na contracapa de Prière d'insérer (primeiro contato com a leitura que manipula o livre objeto) que serve como qualquer tipo de aviso na delimitação do perímetro da diferença entre o animal e homem, a partir da exigência deste último de observar as prescrições das regras que

${ }^{1}$ Por exemplo Lord Auch (Histoire de l'œil, 1928), Louis Trente (Le Petit, 1934) ou ainda Pierre Angélique (Madame Edwarda, 1937).

${ }^{2}$ BATAILlE, Georges. L'Erotisme. Paris: Editions de Minuit, 1957. 
fornecem uma linha de conduta e proibições que servem como frustração. Se elas são necessárias, em um primeiro momento, como fronteiras e limites dentro dos quais o social procura se organizar e, portanto, não se afundar uma dissolução fatal para a sua perpetuação, elas permanecem ambíguas, uma vez que também se referem igualmente a capacidade do homem de transgredir, violar, e percorrer caminhos proibidos. Esta transgressão, por sua vez, não deve ser traduzida como um ato de ignorância de quem a comete, mas sim em uma forma de coragem. Assim, como afirma Bataille ainda em Prière d'insérer, "a coragem necessária à transgressão é uma conquista do homem", que o remete, em geral, a uma experiência festiva ${ }^{3}$, a uma revolta política, a uma atividade erótica, a rir, a apostar no mal e na morte, porém dentro da Literatura e, particularmente dentro da poesia, que manipula constantemente a circulação, seja do choque, seja da alienação, na invenção do mal, ou seja, sua descoberta à invenção de caminhos para sua travessia. $\bigcirc$ mal é essencialmente o modo de desafiar a morte que atrai e estende a vida loucamente.

Como tal, o escritor tem consciência de sua culpa e "ele pode reivindicar o gozo de uma febre, que é um sinal de elevação" (BATAILLE, 1957, p.438). A Literatura é assim um dos lugares privilegiados da expressão da polimorfia e da duplicidade do mal. Ela é uma espécie de purgatório para o homem que interpreta o papel de aprendiz de feiticeiro, numa extremidade do inferno que ele vive vicariamente, sem dúvida um ato de vazio para o escritor, quem comete o ato da escrita e é prejudicado.

A propósito deste ato de purificação, podemos recordar aqui a análise iniciada por Georges Bataille com o psicanalista Adrien Borel, em meados de 1920. Histoire de l'œil, publicado em 1928 sob o pseudônimo de Lord Auch, é de alguma forma o resultado desta análise literária de transformar a violência ficcional dentro do paciente. Foi também uma oportunidade para o autor de adquirir conhecimentos de fotografias do "Supplice des cent morceaux", que congelou o insuportável reencontro do sofrimento com o êxtase $e^{4}$.

\footnotetext{
${ }^{3}$ Ver WunemburgeR(1977), Joron (2012).

${ }^{4}$ Ver Surya (1987).
} 
Uma bela definição para "l'emporte-pièce" de Georges Bataille, no entanto, ausente do teste em questão, pode nos ajudar a limpar o terreno 5 para a soberania do mal na literatura, isto é, na reflexão da existência: "l'homme est ce qui lui manque". (BATAILLE, 1970, p.419). A fórmula pode ser surpreendente. O autor parece referir-se indiretamente à sua leitura da fenomenologia de Hegel (1941) de que os homens e as sociedades avançam por negações sucessivas de suas condições atuais e uma busca incansável de que eles podem a vir desenvolver mais. Alexandre Kojève (1988, p.404) compreende tal movimento da seguinte maneira: "Como o homem não é consciente de sua nova situação no mundo, em comparação com o velho (ancião), ele não pode ver a contradição (ou seja, a negação) que isso implica; ele não pode negar sua ação, e, portanto, sua ação não será verdadeiramente humana ou histórica. [...] Mas a história é uma revolução permanente, à medida que progride por meio da negação da sociedade". O homem é, de fato, o que lhe falta, constituído do que é e do que não é, do que não tem ou do que deveria ter, do que ele não sabe ou acredita saber de si mesmo e do mundo ${ }^{6}$. Ele é ainda o que poderia perder, é portanto este desconhecido que lhe abre qualquer porta da salvação para que, enfim, ele se aceite em toda a sua totalidade, isto é, em sua incompletude total. Assim, o mundo da heterogeneidade e do sagrado, da comunicação e da soberania, ou o mundo da liberdade somada, é, em qualquer ponto distante da ideia do mesmo projeto, baseado na separação do sujeito e do objeto (o outro, o animal, a natureza) em uma relação unilateral de subserviência e de alienação que, a longo prazo, pode retornar para ele mesmo. Este mundo da heterogeneidade é o contrário do lugar da expressão, o que Bataille (1961, p.65-66) chama de "negatividade desempregados", isto é, a aceitação de um destino, ou os caprichos da vida, propulcionado por um grande "sim" à existência. É o que age dentro de um universo que nós encontramos de forma intermitente no canto do

\footnotetext{
${ }^{5}$ Nota do Tradutor: limpar o terreno no sentido de abrir a mente para uma nova idea ou conceito.

${ }^{6} \mathrm{O}$ autor remete elegantemente à noção de total desenvolvimento de Martin Heidegger. Ver Joron (2010).
} 
olho e que sempre remete a nós, insistentemente. Isso insulfla em nós então, surpreendentemente, o choque para a provocação do conteúdo que perturba e nos empurra à alienação de nós mesmo, com maestria, a nossa própria deserção. Sem sombra de dúvida, essa concepção tem um papel central na filosofia de Bataille, que se opõe ainda à sociologia sagrada. Consequentemente, ele irradia ao longo de sua obra literária guias de orientação do olhar presente em sua literatura mais recente, em geral, e em sua poesia, em particular. Assim, em seu prefácio à segunda edição de uma coleção de textos que constitui La Haine de la poésie, denominado L'Impossible, Georges Bataille (1971, p.102) divide a condição humana em duas possibilidades: "Há diante da espécie humana uma dupla perspectiva: de um lado, o prazer violento, horror e morte - exatamente a poesia - e, na direção oposta, a ciência e o mundo real da utilidade". Esta afirmação reflete a tese publicada em 1933 em La Notion de dépense, sobre o princípio da perda, o trabalho ainda permanece uma linha divisória entre o mundo da produtividade, uniformidade e utilitário (econômico, científico, moral) e suas dinâmicas contrárias.

Tal concepção de vida, que são mundanas, sociais ou intelectuais, é provada em muitos exemplos tirados de experiências conjuntas obtidas por Georges Bataille em palestras e conferências realizadas entre 1937 e 1939, na área da Sociologia. Essas experiências, então, fizeram uma reforma heurística, sob a égide de uma atenção particular aos temas de energia e de consumação. É, de fato, em 1949, que aparece La part maudite, que parte da economia genérica dos atores políticos e sociológicos dentro de atividades humanas com o uso de energia vital em duas direções: para capitalizar ou dispensar (gastar). Como outros organismos vivos, a raça humana utiliza parte dessa energia para se procriar, se manter e se sustentar. Mas ela não é totalmente absorvida só nessas realizações. $\bigcirc$ homem deve, então, queimar o excedente de atividades não-produtivas, arte desnecessária, desviante ou imoral, guerra, jogo, literatura, festival, o erotismo, o sagrado. Em La littérature et le mal, Georges Bataille leva o tema da energia, aplicando-o para o poético e pictórico William Blake que, constantemente, tira do 
cadafalso $^{7}$ a razão e a moralidade para ter mais seu desejo de liberdade, que em alguns pode se converter a loucura: "o homem da moralidade condena a energia que lhe falta. A humanidade deve, sem dúvida, passar por ele deixando escapar a viabilidade de não denunciar um excesso de energia confuso; em outras palavras: o nome daqueles aos quais falta a energia remete à razão dos que erram muito. Mas a necessidade da aposta no fim pode retornar à inocência" (BATAILLE, 1957, p.237). Essa dispensa de energia na Literatura, que libera conteúdo pouco recomendado, é sinônimo para Bataille (1957, p.172), de "infância finalmente encontrada", de "retorno à simplicidade perdida” (BATAILLE, 1957, p.172).

Outros conceitos podem nos ajudar a compreender o sistema de desconstrução que vemos em toda obra de Georges Bataille, um sistema heurístico que deseja formalizar um tipo de programa de pensamento, especialmente o pensamento de esquerda, para um esboço ou terreno baldio: a heterologia, a qual Francis Marmande (1985, p.18) nos diz que ela "se dá para pensar os corpos estrangeiros" e que corresponde, nas palavras de Bataille (1970, p.61), à "ciência do que é diferente". É, portanto, a ciência de elementos heterogêneos, expurgado pelas sociedades modernas, que são naturalmente entendidos como expressões do mundo da homogeneidade. Ela corresponde a um campo de pensamento subversivo que pretende não só mostrar o que é deixado para trás - a vida improdutiva -, mas também trazer compreensão de todos estes fenômenos, atividade a qual os homens sérios ignoram, apesar de serem constituídos por elas. É, definitivamente, a ciência da parte maldita (BATAILLE, 1949).

Georges Bataille introduz esta ciência em um texto pré-guerra intitulado La valeur d'usage de D.A.F. de Sade, a partir de uma distinção natural, mais precisamente orgânica, entre o que é a propriedade como uma atividade introdutória do processo fisiológico e o que se resume a excreção residual como uma culminação dessa primeira atividade: "A noção de corpo estranho (heterogêneos) permite a marcação da identidade elementar e primária subjetiva

${ }^{7}$ Nota do tradutor: Lugar onde os condenados sofrem a pena capital. 
dos excrementos (esperma, menstruação, urina, fezes, materiais fecais) e tudo o que poderia ser considerado como sagrado, divino ou celestial (BATAILLE, 1970, p.59)". Nesta metáfora, o indivíduo e a sociedade produzem e consomem uma série de alimentos - física e espiritualmente - para manutenção de seu próprio equilíbrio, mas que chega perfeitamente a ser comandado por uma atração de um "tumulto psicológico" susceptível de desorganizar momentaneamente ou de maneira irreversível a organização mínima proposta para uma manutenção da vida. Georges Bataille (1970, p.59-60) reforça suas observações da seguinte forma: "o processo de apropriação se caracteriza assim por uma hegemonia (um equilíbrio estático) do autor de posse de objetos como resultado final, enquanto a excreção se apresenta como resultado de uma heterogeneidade que, cada vez maior, libera impulsos ainda que ambivalentes, cada vez mais pronunciados. Esses dados metabólicos servem, por assim dizer, como um pretexto para que Georges Bataille (1970, p.66) desenvolva, nas páginas seguintes do texto, uma especíe de manifesto político que dá pleno sentido e é capaz de ligar "o desenvolvimento da prática da heterologia ao reverso da ordem estabelecida”. Além dessa intenção dilapidada e vingativa apegada necessariamente ao contexto histórico que vai surgir, é interessante sublinhar a simbologia que é posta em jogo para anunciar, na ótica de Bataille, a irredutibilidade dos fatos disposta no vazio da vida social.

Tanto a produção ou a secreção corporal é também compreendida como um dado heterogêneo, como uma substância estrangeira à homogeneidade do corpo e, como tal, após ser evacuada, terá que passar por um processo de transformação complexo antes de poder ser reintegrada ou reconquistar o status de um elemento indispensável à manutenção da vida. Nesse sentido, torna-se inevitável, pensar nos "symboles catamorphes", os quais Gilbert Durand (1984, p.133-134) aponta que são partes da queda e da intimidade da carne em relação ao tempo, o que, inevitavelmente, não pode ser entendido sem a angústia: "A carne, este animal que vive em nós, sempre remete à meditação do tempo. E ainda que a morte e o tempo sejam refutados ou combatidos em nome 
de um desejo polêmico da eternidade, a carne em todas as suas formas, especialmente a carne menstrual da feminilidade, será reduzida e reprovada como uma aliada secreta da temporalidade e da morte". Isso seria tudo e por tudo um horizonte simbólico da condenação moral que se desenha à luz de todas as relações humanas; horizonte que se mistura à obsessão da lavagem e purificação. Isso concentra igualmente a atividade excremental, mesmo como observa Gilbert Duran (1984, p.301-302), que nem sempre tem sido desvalorizada, ainda que certas sociedades acordam em atribuir a ela "um papel terapêutico ou de cosméticos" que não é nada secundário, ao mesmo tempo, sem dúvida, para uma criança, em fase de descoberta de sua anatomia e dos jogos que ela suscita, especialmente com tal matéria, são constitutivas do desenvolvimento: "para a criança, a defecação e mesmo a produção de excrementos é valorizada porque é o primeiro produto criado pelo homem". Esta última observação é extremamente importante para o sistema ótico que nos interessa aqui. Sem ir mais longe na direção de imagens e símbolos que cobrem a base hermenêutica, podemos, porém, dar crédito e estabelecer um paralelo entre este tipo de produção orgânica consumida dentro de um certo número de experiências julgadas subversivas que ajustam cada indivídio a um outro tipo de produção, que pode ser de ordem econômica e filosófica e que engloba o conjunto das atividades sociais.

Em termos da heterologia sociológica, a efervescência literária ou poética, como qualquer outra atividade improdutiva de qualquer lugar, se assemelha perfeitamente a seus dados heterogêneos irredutíveis que a homogeneidade do corpo social não pode sofrer sem um pouco de desconforto, sem perturbação mais ou menos acentuada de suas funções vitais, mas que o faz viver em absoluto. Com evidência, a Literatura não muda o mundo, daí a sua inutilidade, mas restabelece o lado escuro jogando sobre as perspectivas e permitindo satisfazer parcialmente irreparáveis necessidades da imaginação. Nós podemos dizer sobre o centro da linguagem da heterologia que "em última análise, está claro que um empregado trabalha procurando a satisfação violenta do coito (isto é, ele acumula para gastar) (BATAILLE, 1970, p.65)”. Em 
suma: como o singular se alimenta do plural, a homogeneidade não pode existir sem um número de componentes heterogêneos que participam de um mesmo corpo, de seu funcionamento e, portanto, de sua unidade vital.

Em La littérature et le mal, Georges Bataille nos lembra que a dicotomia homogeneidade e heterogeneidade foi expressa pela primeira vez em um texto de 1933, sobre o conceito de despesas. De acordo com ele, a humanidade possui duas finalidades: uma negativa, que consiste em conservar a vida (evitando ou adiando a morte), e outra positiva, que remete à obrigação de se aumentar a intensidade da vida. O autor retorna, portanto, ao dualismo Duração / Intensidade. Se a duração pode ser definida como um bem, a intensidade, é assim, um valor. Este valor está além do bem e do mal, no qual Bataille estabelece uma "hipermoral" ou, talvez, para usar aqui o estudo do filósofo Jean-Marie Guyau (1930), um "esboço de uma moral sem obrigação ou sanção". Portanto, ele age sobre uma moral que sabe da culpa que é o esforço da vida.

A Literatura manipula o mal dentro de seu significado ontológico, como o fundamento do ser. Ela brinca com objetos, coisas, situações repulsivas que, por sua vez, continuam a nos atrair. Bataille retoma sua proposta com a ajuda de dois conceitos chave já formalizados no âmbito de suas atividades no Collège de Sociologie: o núcleo social e a interação humana ${ }^{8}$. O núcleo social é compreendido como um conjunto de objetos, crenças, pessoas, lugares, de práticas de caráter sagrado, ou seja, separada da vida profana. Ele, por conseguinte, refere-se, por exemplo, ao sangue, ao fluxo menstrual, aos crime, ou às excreções já mencionadas. $\mathrm{Na}$ verdade, o núcleo social é essencialmente um tabu, objeto de uma repulsão fundamental: uma repulsão comum que se consolida durante o vínculo entre os indivíduos. Como tal, o desgosto, o terror, o horror servem de laço para reunir objetos relacionados ao sexo e à morte. Estes são elementos heterogêneos que atraem, fascinam e aglutinam cujo caráter sagrado é indiscutível. O sagrado é aqui, então, "a transformação de conteúdo depressivo em objetos

\footnotetext{
${ }^{8}$ Georges Bataille. Collège de sociologie. Conférences du 22 janvier et du 5 février, 1938.
} 
de exaltação" (BATAILLE, 1970, p.317). Portanto, a repulsão provoca a atração, enquanto a depressão provoca excitação. Inevitavelmente, a interação humana se faz mais intensa em torno desse núcleo social e sagrado. Entendido como uma sensibilidade dos trópicos que provoca a conexão entre os indivídos - e permite a Georges Bataille (1970, p.308) explorar, mais adiante, "a mola essencial da máquina humana” -, provoca uma forma de agrupamento em torno de um núcleo comum feito de representações, de práticas, de intenções e impulsos, de objetos e seres sobre os quais eles estão se atualizando. Sob o pretexto de um imediatismo quase exclusivamente instintivo, a interação humana não pode existir socialmente mediada por um conjunto de sinais distintivos ou, mais precisamente, em função de sua passagem obrigatória por conteúdos sagrados do "núcleo social", que a distingue dos outros animas que, naturalmente, não podem encontrar referência no sagrado: "a interação humana não é imediata, ela está dentro do senso preciso da palavra médiatisée, isto é, a ligação entre dois homens é profundamente alterada à medida que eles se situam em uma outra órbita do núcleo central: o conteúdo essencialmente terrificante do núcleo em torno do qual a existência de cada gravidade envolvida intervém dentro da relação como um meio termo inevitável (BATAILLE, 1970, p.311). A Literatura, assim como poesia e o sentimento religioso, pode, portanto, ser entendida como um núcleo social ou sagrado, porque não está em nós, "nos expulsa" em objetos, situações e pessoas retratadas à luz do drama que nos prende. Ela é o mau, ou "o diabo, que é a pura essência da poesia". Ela é ainda "o consentimento do homem com seu próprio desgosto e, por fim, a sua concordância com a morte, com o movimento que é precipitado (BATAILLE, 1957, p.226 e p.231)".

Ainda em La littérature et le mal, Georges Bataille, 1957, p.300) introduz duas outras noções de estado totalmente complementares: de soberania e de comunicação: "a Literatura é comunicação. Ela parte de um autor soberano, passa pela servidão de um leitor isolado, e se destina a uma humanidade soberana". De acordo com comentário feito por Mario Perniola (1982, p.35), em L'instant éternel, este tipo de comunicação é o oposto da troca, 
que é a base das relações econômicas e da linguagem comercial. Para Bataille (1957, p.314), é o estouro de uma heterogeneidade irredutível: "a maior parte da comunicação não pode ser feita com a condição de que nos recorramos ao mal, isto é, uma violação da proibição. Para isso, é preciso dramatizar. A Literatura deve viver o drama. Sem o drama, não seria possível "sair de nós mesmos" e se comunicar com o exterior de maneira indescritível. Assim, "a comunicação é o contrário da coisa que se define pelo isolamento, que é possível de fazer (BATAILLE, 1957, p.301)”. Ela é soberana, autêntica ou majoritária à condição de não ser servil ou subordinada. Faz da obra literária uma operação soberana que aposta numa comunicação que envolve o jogo sagrado, isto é, de objetos de repulsão (sexo, morte) que quebram o isolamento do ser.

Para dizer de outra forma, é o feixe de perspectivas que visa a questão da soberania na arte, na poesia, na literatura, dentro de uma relação que une o ato de criação e sua recepção, retrocedendo um retorno de emoções, mas ainda dentro da sociedade existencial, da religião, da guerra, do erotismo, dos partidos, da vida cotidiana, nessas breves formas de vida social que experimentam a cada instante o gasto improdutivo a partir do momento que o sagrado é parte envolvida. Soberania, mas em comparação a que? Ao que Georges Bataille chama de vida produtiva, a homogeneidade ou esfera de atividade: como explica Philippe Audoin (1987, p.16), ao comentar a crítica de Bataille ao mundo moderno, à sua ideologia e a quem a usa, "o que não é soberano é definido como escravo ou subordinado. Tais são os comportamentos que estão associados com um projeto, que escravizam a obtenção de um resultado, cuja razão fundamental é, em última instância, preservar, valorizar, perpetuar o indivíduo, a espécie”. A posição situacionista de Guy Debord (1989), no entanto, após a demarcação de Bataille, também nos dá uma ideia bastante precisa do movimento, qualificado por Georges Bataille (1957, p.312), como fulgurante, contido na abordagem da soberania pela arte, pela vida como uma forma de arte: "a arte pode deixar de ser um relatório sobre as sensações e tornar-se uma organização direta das sensações mais elevadas. Ele está produzindo nós mesmos, e não coisas que nos escravizam. [...] Deve levar à 
destruição de todas as formas extremas de pseudo-comunicação, para conseguir um dia uma verdadeira comunicação direta. Esta afirmação de Debord, publicada em Internationale Situationniste (n.1), em junho de 1958, repercutiu, em todos os aspectos, a ideia de comunicação soberana de Bataille, descrita em um artigo dedicado à interpretação de Jean-Paul Sartre no trabalho de Jean Genet, publicado na revista Critique (n. 65 e n. 66), de 1952. Neste artigo, que mais tarde tornou-se um capítulo de La littérature et le mal, Georges Bataille (1957, p.312) se dedica a estabelecer uma distinção entre a comunicação forte, que ele concebe como a soberania, e a falta de comunicação, que ele compara a uma atividade servil: "a comunicação forte é primeira, é um dado simplesmente, a aparência suprema da existência, que nos é revelada na multiplicidade de consciência e de sua comunicabilidade". Esta duplicidade comunicação forte / comunicação fraca - ou para buscar a dicotomia de Debord comunicação real direta / pseudo-comunicação -, se aplica à exploração de uma divisão do mundo, da existência entre o sagrado e o profano, entre soberania e subordinação, entre consumação e consumo, entre comunhão e isolamento.

Os literários sabem bem que existe uma dimensão erótica no ato de criação, que dá à obra uma dimensão de ser alienada. Primeiro, um erotismo de expressão, que, a seu modo, serve para perfurar o silêncio ou inércia: as palavras, a sintaxe, o ritmo. Mas há também um objeto tátil específico com o qual se imprime o traço: caneta, teclado, tela e papel. Depois, tem-se um erotismo de ligação ou um vínculo fugaz entre aquele que faz e aquele ao qual se destina a obra. Este tipo de erotismo é mais intenso porque ela brinca com a descoberta do outro, entre uma exposição assumida e uma nudez negociada. Sobre um registro ao mesmo tempo sensual e místico, Bataille (1987, p.312) previu três formas de erotismo: o erotismo do corpo, o erotismo dos corações e o erotismo sagrado, que envolve os dois primeiros. $\mathrm{O}$ erotismo, como valor, é definido principalmente em oposição a reprodução sexuada, entendida como duração. Ele tem então o ofício, entre outros objetos de repulsão transgressiva, de um núcleo sagrado que dá acesso a um estado de continuidade com o outro, ou com 
os outros, com o que Bataille compreendeu ainda como estado de intimidade perdida. Aplicado à Literatura soberana e ao instante de corpos que se cruzam, se roçam, se afrontam, e se misturam às vezes, evidencia-se assim o erotismo provocado por uma estética comum, ou seja, ao fato de sentir juntos uma emoção, de sensações partilhadas. Mais ainda que dar uma estética à obra, ele é o local de derrame de uma conexão que nos abre à sensação plena de nossa existência. $O$ erotismo literário é, sem dúvida, um corpo a corpo diferido entre autor(es) e leitor(es), feitos de produções e recepções solitárias, mesmo que os dois participem do mesmo ato, o que Hannah Arendt (2005) denominou "a solidão", a desolação de uma viúva em si qualquer ato de duplicidade.

Dissemos anteriormente que Bataille (1970, p.345) definiu o homem de acordo com o que lhe faltava. Isto refere-se, sem dúvida, ao problema da diversidade, que é também incluída como uma "diferença que não pode ser explicada". Nós não estamos definidos de uma vez por todas. A duplicidade causa incessantemente o sulco em nossas diversas tentativas de identificação por ação ou por procuração, que nos traz uma sensação de completude para escapar. Em La part du Diable, Michel Maffesoli (2002, p.117) indica bem o leque de possibilidades em estado de experimentação, que visa o vitalismo social no acesso ao outro: "é um trabalho pela falta não pode favorecer a pesquisa do eu mesmo, na vida social, na natureza, na divindade, no outro que, por um momento e de modo imperfeito, me completa”. Estamos acenando para experiências que nos constróem e são sublimes num tempo determinado em sede de busca por novas sensações. Um especialista da psique humana diria, sem dúvida, que cada um de nós, ao seu nível, com base em sua própria história, mas também em suas próprias determinações existenciais, em função ainda ou apesar de muitas restrições (social, familiar, cultural, econômica etc .) alimentando o sentido da vida, cada um de nós, portanto, convoca a necessidade de experimentar o que não é óbvio, o que não é evidente à primeira vista. Precisamos descobrir novos horizontes de nós-mesmos, e necessitamos igualmente nos ouvir e darmos respostas ao que é diferente, ou seja, às outras situações 
mundanas, mas também a uma parte de si mesmo que a "educação social" tende a desacreditar, enterrar, ou colocar de lado. Voltamos para a circularidade do complexo choque / alienação introduzido anteriormente. Para inserir uma nova experiência, ou outro, ou trama em si, ainda é necessário abrir mão de algumas convenções colocadas em conformidade pessoal em relação aos outros. Em outras palavras, é conveniente se soltar. Esta tomada de risco sem válvulas de segurança, em seguida, implica uma prestação de contas que, sem dúvida, é a iminente aniquilação de si mesmo, dos outros, de um mundo que serve de suporte para apostas de relações entre obras. Emile Cioran (1964, p.172) defendeu a concepção de "hurloirs", um tipo de derramamento de emoções, experiências (arte, festas, esportes, literatura, em parte). É o que ainda nós podemos chamar de experimentos ou de laboratórios existenciais que permitem brincar com o fogo sem riscos de ocorrer um incêndio generalizado que provocaria ausência ou destruição. Talvez, convém entender esta variável humana constante, a atração do mal, dentro de um quadro de alterologia constitutiva (Joron, 2006): um pensamento sobre outro que se altera, tanto no sentido de alternância, mas também se desestabiliza com elegância a grandes golpes de alteridade em face da seca muito similar, até a aridez da identificação. Já precisamos em outro local que esta alterologia não só é aplicada ao estudo da ação social e de suas produções imaginárias, mas ainda às relações que o pensamento estabelece em seus terrenos de expressão levando em consideração, pelo menos, quatro dimensões: desapropriação, comunhão, procuração, interação (JORON, 1999, p.51-71), e outras maneiras que significam os mecanismos de acesso ao outro.

Essa problemática da alteridade, alternância ou alteração que completa e realiza o homem está no próprio centro da Literatura verdadeira e soberana. Como o disse o jornalista realista Albert Londres, é conveniente "levar a caneta na ferida", ou seja, colocar o cursor nos poros do real. Isto também tem valor à Literatura que colocamos em questão, aquela que manipula, com boa sabedoria que, por vezes, nos fazem morder os dedos, os ingredientes heterogêneos da parte maldita. 


\section{PHILIPPE JORON}

\section{Referências}

ARENDT Hannah. La vie de l'esprit. Paris : PUF, 2005.

AUDOIN Philippe. Sur Georges Bataille. Paris: Actual / Le temps qu'il fait, 1987.

BATAILLE Georges. Le coupable. Paris: Gallimard, 1961.

. La part maudite. Paris: Éditions de Minuit, 1949.

- La structure psychologique du fascisme. Guvres Complètes.Tome

I. Paris: Gallimard, 1970.

. La Notion de dépense, la critique sociale, n. 7, p. 7-15janvier 1933.

CEuvres complètes, Tome I. Paris: Gallimard, 1970. p. 302-320.

- Collège de sociologie, Conférences du 22 janvier et du 5 février 1938. CEuvres complètes, Tome II, Paris Gallimard, 1970.

. La valeur d'usage de D.A.F. de Sade. CEuvres complètes, Tome II. Paris: Gallimard, 1970.

- L'Impossible (La Haine de la Poésie), Editions de Minuit, 1962

(1947). CEuvres complètes, Tome III. Paris: Gallimard, 1971.

. La littérature et le mal, Paris, Gallimard, 1957. CEuvres complètes, Tome IX. Paris: Gallimard, 1979.

- Jean-Paul Sartre et l'impossible révolte de Jean Genet, in Critique, $\mathrm{n}^{\circ}$ 65, octobre 1952, p. 819-832 et n 66, novembre 1952, p. 946-961. CEuvres complètes, Tome IX. Paris: Gallimard, 1979.

. L'Erotisme. Paris: Editions de Minuit, 1957. CEuvres complètes, Tome X. Paris: Gallimard, 1987.

CIORAN Emile. La chute dans le temps. Paris: Gallimard, 1964.

DEBORD Guy. Thèses sur la révolution culturelle . Internationale Situationniste, n.1, juin 1958 .

DURAND Gilbert. Les structures anthropologiques de l'imaginaire. Paris: Dunod, 1984. 
EHRWAIN NIHAN Céline. Hannah Arend : une pensée de la crise. Genève: Labor et Fides, 2011.

GUYAU Jean-Marie. Esquisse d'une morale sans obligation ni sanction. Paris: Félix Alcan, 1930.

HEGEL G.W.F. La phénoménologie de l’esprit. Paris: Aubier, 1987

JORON Philippe. LHétérologie sociologique. In : PIBAROT, Annie (Dir.). Georges Bataille, l'héritage impossible. Montpellier: PULM, 1999. p. 51-71.

(Dir.). Violences et communication. Approches franco-brésiliennes des altérités communicationnelles. Montpellier: PULM, 2006. Les Cahiers de l'IRSA, n.6.

. La vie improductive. Georges Bataille et l'hétérologie sociologique. Montpellier: PULM, 2010.

. La fête à pleins bords. Bayonne: fêtes de rien, soif d'absolu. Paris: CNRS Editions, 2012.

KOJEVE Alexandre. Introduction à la lecture de Hegel. Paris: Gallimard, 1988.

MAFFESOLI Michel. La part du diable. Précis de subversion postmoderne. Paris: Flammarion, 2002.

MARMANDE Francis. Georges Bataille politique. Lyon: PUL, 1985.

MARTOS Jean-François. Histoire de I'Internationale situationniste. Gérard Lebovici, 1989.

PERNIOLA Mario. L'instant éternel. Paris : Méridiens/Anthropos, 1982.

SURYA Michel. Georges Bataille, la mort à l'œuvre. Paris: Séguier, 1987.

WUNEMBURGER Jean-Jacques. La fête, le jeu et le sacré. Paris: Delage, 1977. 